\title{
MANUEL PUIG: LAS RELACIONES PELIGROSAS
}

\author{
POR \\ JORGE PANESI \\ Universidad del Salvador, Buenos Aires
}

Una realidad eje y dos mitologías conexas (forjadas en los códigos sociales y en sus espejismos ideológicos) sostienen siempre la narrativa de Manuel Puig: la realidad que subyace en la fabulación es la diferencia de los sexos; las mitologías irrisorias, imposibles, que tejen los personajes son lo masculino en sí -el hombre ideal-y el «eterno» femenino - la esencia de la femineidad.

Un hombre, Molina, es el prototipo de lo mujeril; la belleza masculina relumbra en el donjuanismo pueblerino de Juan Carlos (y se repite en el proletario Josemar); un vacío primitivo, producido por la figura del padre, se colma mediante una conversación paterno-filial en la que se tratan de aclarar los misterios del poder masculino y de la ley ${ }^{1}$. El pensamiento acerca de estas diferencias se revela esencial para los presupuestos que rigen la génesis de su universo narrativo.

\section{DE LA VOZ A LA ESCRITURA}

La traición de Rita Hayworth en su disposición misma indica el proceso que ha de narrar: voces indiferenciadas en los capítulos iniciales,

${ }^{1}$ En El beso de la mujer araña (Barcelona: Seix Barral, 1976), Boquitas pintadas (Buenos Aires: Sudamericana, 1969), Sangre de amor correspondido (Barcelona: Seix Barral, 1982), La traición de Rita Hayworth (Buenos Aires: Jorge Alvarez, 1968) y Maldición eterna a quien lea estas páginas (Barcelona: Seix Barral, 1980), respectivamente. Citamos La traición de Rita Hayworth por la 7. edición (Buenos Aires: Sudamericana, 1974), abreviando LTRH; Boquitas pintadas por 1a 16." edición (Buenos Aires: Sudamericana, 1974) y Pubis angelical por la 1. ${ }^{a}$ edición (Barcelona: Seix Barral, 1979). Los subrayados de las citas, en todos los casos, nos pertenecen. 
escritura en los finales. Bildungsroman, muestra a través de qué peripecias, malentendidos y circunstancias previas alguien se hace escritor; Maldición eterna a quien lea estas páginas (novela de reiniciación) vuelve sobre el mismo tema, contando cómo un hombre, pasada su treintena, $\mathrm{y}$ a punto de perderse ${ }^{2}$, inicia una actividad que ha de autoafirmarlo: aquí la novela, semejante a la anterior, parte del diálogo entre dos voces y concluye con un epílogo escrito en forma epistolar.

La lectura de los dos primeros capítulos de LTRH sumerge al lector en la imprecisión -en la confusión- acerca de los locutores predominantemente femeninos. Hay allí una ausencia que ocupa ya su lugar en ese universo simbólico determinante -el «nenito» innominado, Totoy dos voces masculinas ahogadas, tapadas, cubiertas, escondidas por ese diálogo: el abuelo materno (cap. I) y Berto, el padre (cap. II), en trance de escribir la carta que, a modo de revelación, encontraremos al final.

Tejido (texto) urdido por mujeres, la novela se autorrepresenta en sus primeras frases: «Me dio más trabajo este mantel que el juego de carpetas que son ocho pares...» (p. 7); LTRH tiene dos pares (partes) de ocho capítulos cada una y lo que teje - para destejerlo- es un ocultamiento, una ilusión apresada en reverberos incantatorios ${ }^{3}$. Lo femenino, la voz femenina es lo que fascina, $y$, por tanto, promueve la imitación; pero también, según la ley de autoengendramiento del corpus, la reproducción es un posible ocultamiento, una trampa, una traición, una mentira.

\section{LA COPIA Y LA ORALIDAD: PRINCIPIOS FEMENINOS}

Lo femenino rige el principio de copia y reproducción en una escritura consagrada como hábil para registrar los más finos matices del habla. Puig mismo concibe los orígenes de su actividad novelística en términos de reproducción; lo que el escritor naciente reproduce en el instante primero es una voz femenina: «[...] recordé la voz de una tía.

${ }^{2}$ Dos caras de la misma iniciación: «[...] $L T R H$, que es un poco mi infancia y la explicación de por qué yo estaba en Roma, a los treinta años, sin carre$\mathrm{ra}$, sin dinero [...]. Escribir esta novela fue tratar de comprender mejor este fracaso» (reportaje a Manuel Puig por Saúl Sosnowski, Hispamérica, núm. 3, 1973, p. 71). Larry, de Maldición, a punto de «encaminarse», tiene treinta y seis años, la misma edad de Puig al publicar su primera novela.

${ }^{3} \mathrm{La}$ apertura y cierre de cada parte coincide con el eje masculino-femenino: la primera se abre con las voces femeninas en casa de Mita y concluye (capítulo VIII) con el monólogo de ésta; la segunda comienza con Héctor (familia paterna) y concluye con la carta del padre. 
La voz de ella me vino muy clara [...]. Empecé a registrar esa voz [...]. A lo único que me animaba era a registrar voces» ${ }^{4}$. La oralidad es una característica insistente en Puig (Maldición, El beso y Sangre de amor correspondido son fundamentalmente diálogos); LTRH confirma esta prominencia de lo oral ligándola con lo femenino en un episodio que podríamos llamar «la representación de una escena de lectura», por dos veces se nos cuenta (p. 53, p. 85) que Mita lee el diario "en voz alta» a Berto: una voz (femenina) que (se) lee.

Toto reflexiona sobre este principio de la copia durante lo que en el texto es la escena originaria de la escritura, la siesta parental: "Sin modelo no sé dibujar, con modelo dibujo mejor yo» (p. 73). La madre es el modelo primero, pero ella misma se rige por la copia ${ }^{5}$ : ha elegido a Berto porque se parece, en su belleza, a un artista de cine; Berto es la copia de su primer modelo/novio cinematográfico, el actor Carlos Palau (pp. 19-29). Así como su madre ha dibujado para él los «cartoncitos» - copia gráfica de los films-, Toto "copiará» una película en su primer intento literario. Mita tiene dos deseos que Toto colmará uniéndolos en su composición: el cine y las letras (quiso inscribirse en la Facultad de Letras y tiene «la locura del cine», pp. 18-19).

En un principio Toto, capturado en esta ley repetitiva, sólo puede ejercitar una mímesis sin entenderla del todo: dibujará el aparato digestivo-reproductor "como habla un loro» (p. 76). Loro que él mismo convierte -feminiza - en «loritas», animalejos fascinados por la luz, pero que «no ven, son como ciegas» (p. 115). Estas «loritas» se estrellan contra un cuaderno (la escritura) y muestran el otro principio antagónico del hablar-repetir: ver es saber ${ }^{6}$; escribir (leer) es revelar lo oculto. E1 gran peligro que $L T R H$ esquiva es ese «no saber»: «por la luz que me alumbra, que me quede ciega» (p. 27), jura Amparo, la sirvienta. Las

${ }^{4}$ Sosnowski, op. cit., p. 71. E1 sistema Puig introduce una mutación importante a partir de Pubis angelical: la reproducción del habla se trueca en traducción. Una argentina dialoga y «traduce» modismos porteños a una mejicana, ésta hace lo mismo con los mejicanismos. Maldición y Sangre lo incorporan como proceso genético: estas novelas, en su totalidad, se declaran traducción del inglés y del portugués (idiomas en los que - hay que suponer- los personajes dialogan).

${ }^{5}$ Parecido principio en Maldición, donde Larry dice: «Mi madre no tenía palabras propias» (p. 102).

'Como señalara para las «ciegas» de Boquitas pintadas (Nené y Celina) Josefina Ludmer en su lectura «Boquitas pintadas, siete recorridos», Actual (Revista de la Universidad de los Andes), Mérida, enero-diciembre 1971, año II, 8-9, p. 21. En el primer capítulo se encuentran significantes que se refieren a la visión en los nombres de los personajes: Ber-to, Vio-leta y la citada Caba-lús, unidos al tema de los anteojos y la vista deficiente de Adela. 
voces femeninas del comienzo mencionan un personaje, una actividad y un lugar que funcionan como antítesis del mundo que ellas representan; se trata de Sofía (sabiduría) Cabalús (luz), la amiga de Mita que, loca por la lectura y encerrada en la biblioteca, ya no aparece más por la casa. Por otra parte, la menos sabia, la anti-Sofía, la que menos ve (tiene miopía), la más «ciega» es, precisamente, Adela, agente introductor de confusión porque hace tambalear la ley paterna (cf. la carta de Berto). Sabiduría y traición son las dos caras «éticas» del principio femenino.

La verdad, tanto en $L T R H$ como en Maldición, se busca y se halla en lo escrito, en la ley paterna que quedó cifrada en los libros (Les liaisons dangereuses) o en una carta. Si el padre escribe en $L T R H$, despeja un enigma de la trama y levanta los velos de una «traición»; por el contrario, el ámbito de Mita coincide con la fabulación: su padre pide que en una carta se la engañe ( Decile que estuviste con Sofía Cabalús, decile una mentira», p. 18). Si Mita escribe, lo hace para fraguar la voz de Delia, miente por escrito en una carta (a los padres de Yamil, p. 128).

En el capítulo IV de $L T R H$ estas coordenadas (copia-oralidad-ocultamiento) coinciden con un personaje paródicamente femenino: Choli, la amiga no letrada de Mita (pero sí espectadora de cine). Es un diálogomonólogo-espejo donde la falta de réplicas de Mita indica que ella misma es la réplica de su amiga, su copia especular. Choli, que habla sola en los hoteles y se mira extasiada en pisos brillosos y en espejos, está construida por entero sobre la temática del reflejo: miente, y para disimular una aventura que ha tenido con un hombre, inventa un doble, otra viuda («viajaba como yo», p. 69) que «al tercer día que lo conoció... le aflojó» (p. 68). Choli vende cosméticos, se pinta, oculta: «con un vestido bien cortado que tape los defectos una mujer queda regia»; " [...] atrae más, parece que oculta un pasado» (p. 72). «Hollywood cosméticos»: el cine en $L T R H$ es un reflejo, un brillo que oculta.

Brillo, espejo $\mathbf{u}$ ocultamiento cifrados en dos objetos que circulan por todo el relato; o, por mejor decir, un objeto (el cubrecama) ${ }^{7}$ y una cualidad ilusoria (el brillo). El cubrecama que tejen voces maternales (capítulo I) cuando irrumpe el «nenito» reaparece en la composición transformado en tul de mosquitero, objeto materno que, escribe Toto, «me cuida bien [...] y me observa [la madre] mejor de lo que soy,

${ }^{7}$ El cubrecama, en efecto, aparece en el monólogo de Paquita (p. 193), en los dos monólogos de Toto (pp. 78-94), en el de Teté (p. 106) y en la composición (p. 281). 
esfumado por la trama de un tul...» (p. 270). Objeto dual: mejora, pero a la vez ahoga, esfuma. En cuanto al brillo, LTRH exhibe una obsesionante apoteosis de lo que brilla y refleja: «brillan como espejos» se dice a cada momento de las superficies que reflejan lo imaginario mismo sujeto a la especularidad, el sueño sin forma de lo cotidiano, lo doméstico, la minucia pequeñoburguesa reflejándose a sí misma, pero brillando amplificada en su propia superficie fascinadora ${ }^{8}$.

En $L T R H$ lo que se escamotea es el cuerpo, el sexo y la identidad (Ricardo Piglia) ${ }^{9}$; por ello, «cubrir», «tapar», «vestir», «velar» y «ahogar» son acciones homologables a «no ver», «no saber». En este mundo novelístico en el que hasta el mismísimo Dios se disfraza (p. 116), rige la ley moral del disimulo. Apresado en esta ley ( el maravilloso ropaje del amor es acto puramente animal», p. 222), Toto hace su entrada en la novela interesado por los vestidos de unos muñecos, por un acto donde los niños se disfrazan y por una careta «rosa» (color de «nenas»).

\section{TOTO/TETÉ: LA CARETA ROSA}

Pintura en cartoncitos, cosméticos, máscara «rosa» o promotor del anhelo mimético (tal la cadena asociativa), en $L T R H$ lo femenino oculta mejor: Toto, que tiene seis años, para esconderse prefiere a los pantalones paternos las polleras de la madre (p. 34).

El disimulo femenil o la propiedad del «espejo que oculta» no es

${ }^{8}$ Jean Baudrillard trató de establecer una retórica objetal de la clase media; entre sus características destaca: la proliferación de elementos que cubren o tapan (indicadores o signos que subrayan la posesión) y el gusto por lo barnizado, brilloso o esmaltado, que reduplica los objetos. Redundancia especular en la que puede leerse «la ecuación fundamental de la propiedad: A es A». «La simetría, junto con la higiene y la moralidad, constituyen la representación 'espontánea' que las clases medias tienen de la cultura» (cf. "La moral de los objetos. Función-signo y lógica de clase», en Los objetos. (Buenos Aires: Tiempo Contemporáneo, 1971, pp. 37-75). El obsesivo brillo en los pisos y el interés por la comida son en LTRH índices de diferenciación social: las sirvientas tienen piso de tierra (no puede brillar), pero reproducen los pruritos de limpieza pequeñoburgueses: «mi casa será un rancho pero barremos el piso» (p. 22); Delia, perteneciente a un estrato más bajo de la clase media, observa: «gente que coma caro como en lo de Mita...» (p. 126); Amparo se muestra arrobada por las milanesas (p. 28).

${ }^{9}$ Cf. Ricardo Piglia, "Clase media: cuerpo y destino (Una lectura de $L T R H$ de Manuel Puig)», en Nueva novela latinoamericana 2 (Buenos Aires: Paidós, 1972). «[...] Toto ha elegido enmascararse...»; «[...] lo que hace es negarse a usar, a vivir su cuerpo» (p. 353). 
solamente anecdótico o explicación de «psicologías», tiene una manifestación estructural en el nivel de los personajes: Teté es el espejo fernenino (la máscara) textual de Toto (nótese la similitud fonética de los sobrenombres). En primer lugar, las dos figuras son inversas y simétricas respecto del eje Mita-Berto: en el discurso de Teté, Mita sustituye a la madre ausente y enferma de la niña (es benéfica: le proporciona un «buen» alimento, la naranja colorada que el monólogo opone a los colores de la fantasía mortuoria -azul, blanco, gris-); del mismo modo, ausente Berto a la hora de la siesta, el padre de Teté lo reemplaza y juega con Toto, cumpliendo así su deseo de intimidad con la figura paterna. En segundo lugar, igualdades: el padre de Teté y Berto no tienen «ni papá ni mamá» (p. 117); a Toto se le prohíben juegos de «nenas» (vestiditos de muñecas, cartoncitos), a Teté le indican que no debe montar a caballo como los varones (p. 104). Teté se identifica con su mamá por medio de la enfermedad, la muerte y la obsesión de rituales, promesas, rezos; Toto se identifica con la suya por medio de otra religión, el cine (y sus rituales: cortar, dibujar, colorear, archivar cartoncitos). La madre de Teté es religiosa; Mita, atea (perfecta simetría). La especularidad de las dos figuras queda dicha en el texto: «se le pegó todo de la Teté» (p. 185).

Lo que fundamentalmente se «esconde» en esta especularidad textual (Toto/Teté) es una relación tanática ${ }^{10}$. Toto, celoso de su hermanito, ha deseado «con el pensamiento» la muerte de su madre; la relación dual, destructiva y mortífera ${ }^{11}$ se desarrolla - o se piensa- en dos monólogos estrechamente ligados entre sí: el de Mita (que narra la muerte de su niño) y el de Teté. En ellos dos se concentra la mayor cantidad de referencias al movimiento de ahogo, de asfixia, que obsesiona a los personajes en Coronel Vallejos ${ }^{12}$. Teté en su discurso ima-

${ }^{10}$ Desde luego, también se «esconde» o se escamotea el narrador: una característica constante en la literatura de Puig.

${ }^{11}$ destructiva y mortifera: un mismo significante cuchillo/bisturi permite unir «madre-hijo» en dos escenas agresivas y tanáticas: a) Toto (p. 142) clava un cuchillo a una sirvienta, acto comentado por Delia: «¿Si está siempre pegado a Mita, dónde se volvió asesino este chico?» He ahí la causa, sería la respuesta. b) Mita, al enterarse de la muerte de su hijo, insistentemente metaforiza su dolor por medio de un bisturí que revuelven en su cuerpo (pp. 155-156).

${ }_{12}$ Ahogo que tiene un agente productor: el polvo, la tierra, característicos de Coronel Vallejos. Por eso Mita, encerrada en su mundo de sueños, ha hecho sellar las puertas para que no penetre el invasor (p. 144). El pueblo (la realidad) y su atmósfera son 10 asfixiante. El cuerpo escamoteado (cf. R. Piglia, op. cit.) vuelve - como lo reprimido- en forma de enfermedades. Predominan las pulmonares, que suponen la asfixia: el nuevo bebé de Mita sufre un ahogo (p. 204); Herminia padece asma y cree estar tuberculosa (p. 291); Celia, tía paterna de Paquita, 
gina cómo Mita ahoga a Toto (p. 119); el bebito ha nacido con un «defecto de respiración» y muere por asfixia; como compensación a esta muerte, Mita empequeñece imaginariamente a Toto casi hasta restituirlo a su cuerpo: «me ha quedado nada más que un brote, un botón» (p. 163), dice haciendo una asociación botánica (Mita ama las plantas). Asociación botánica que no carece de importancia, pues el pequeño Toto, ante las revelaciones sexuales de cierta vecinita, recuerda una devoradora planta carnívora que crece en el fondo del mar. La planta carnívora es una oscura mezcla de terrores fantásticos primitivos, en la que se conjugan lo materno devorador y dos significantes textuales adheridos a lo masculino: el mar y los pelos ${ }^{13}$.

\section{Del ver al contar: Los hombres No CUENTAN ${ }^{14}$}

Terror. Y justificado, pues la novela indica que las posiciones masculinas son, para su héroe, imposibles. Para urdir este destino, dos «traiciones» se alían: la del padre y la de Mita. Esta última acapara la mayor cantidad de dobleces: frente a la ley paterna (de lo cual la carta final es una queja); en sus objetos (tiene dos amigas antagónicas que representan principios opuestos: Sofía vive encerrada, es la intelectual; Choli, la frívola, viaja y, casi ignorante, no sabe dónde queda Londres); en sus objetos-hijos que divide tajantemente: "[su] nene-hombre» (Héctor) y su nene... (Toto) ${ }^{15}$; en el lenguaje: ella, que se muestra «tan fina» -observa Delia-, tiene "una lengua de carrero», etc. Taimadas, escondedoras, de las mujeres que recorren $L T R H$ no se puede estar seguro. Es lo que Toto descubre en una temprana figura femenina, Alicita; quiere ser su novio, pero una imperceptible nadería le infunde descon-

muere por igual causa (p. 190); se citan novelas cuyos protagonistas padecen de tuberculosis: María, El loco, La montaña mágica.

${ }^{13}$ a) Mar. Los dos prototipos del machismo (Héctor-Cobito) están asociados con el agua: Cobito tiene pasión por pescar en el río Paraná (p. 233); Héctor se prepara para ingresar en el Colegio Naval. El modelo de belleza masculina se llama Adhe-mar. Asociación que Herminia, la virgen solterona, confirma: «nunca vi el mar» (p. 313). Nótese que el protagonista de Sangre de amor correspondido es Josemar. b) Pelos: «pelos en el pito» (p. 43); «que se dice cabello, pelo es para los hombres o los animales» (p. 77). En Héctor, con su pasión por los animales, estas cadenas se asocian: una forma de desvalorizar el machismo (p. 170).

${ }^{14}$ Dos procesos de transformación subyacen en $L T R H$ y se narran: $1 .^{\circ}$ ) cómo se convierte la voz en escritura; $2 .^{\circ}$ ) cómo un espectáculo predominantemente visual se transforma en un relato oral o escrito.

${ }^{15}$ Los puntos suspensivos pertenecen al texto (monólogo de Mita): «con él [el bebé muerto] sí que iba a estar contento Berto, no con este flojo, con este... gallina de Toto» (p. 159). 
fianza: «no me contesta si le hablo y me dice mentiras guiñando los ojos» (p. 87).

Moldeada en esta dualidad imaginaria, la ley paterna bascula entre las posiciones irreconciliables del todo-nada. En LTRH como en Maldición su estructura hay que referirla a lo que se conoce como padre ideal o padre idealizado ${ }^{16}$. Contradictorio rostro de Jano, se presenta como una blanda bondad, o bien como sentencia de aniquilación total. «Tu papá es el más bueno de todos», le dicen a Toto; lo que no invalida la amenaza implícita en el otro polo de su ley dual: «el día que te ponga la mano encima te deshago». O todo bondad o aterrorizador poder de destrucción, su inmediatez deshace.

La ley paterna es débil e ineficaz porque vacila: prohíbe que juegue con vestiditos y luego perdona el castigo; dice que «los hombres no lloran» y el hijo descubre el llanto del hombre cuando talan los árboles (que, como veremos, se relacionan, en Puig, con el poder genésico masculino). La «doble faz» (pp. 306-307) se revela en una película que Toto cuenta a Herminia: un señor feudal educa a sus hijos según dos códigos contradictorios y los conduce a un desastre que luego castiga implacable. Al subsumirse en la instancia materna, la posición del padre es la del «bobo», según descubre Toto en la única identificación cinematográfica de Berto: «a papá le gusta cuando [Rita Hayworth] le hacía 'Toro, toro' a Tyrone Power, él arrodillado como un bobo [...] y ella se reía de él que al final lo deja».

$L T R H$, que transforma frases del lenguaje popular en secuencias narrativas ${ }^{17}$, muestra esta debilidad desde el inicio: mientras que el

${ }^{16} \mathrm{Cf}$. Moustapha Safouan, «La figura del padre ideal y sus incidencias sobre la relación del sujeto con la verdad», en Estudios sobre el Edipo (México: Siglo XXI, 1977), y Guy Rosolato, «Del padre», en Ensayos sobre lo simbólico (Madrid: Anagrama, 1974). La dualidad de la ley paterna, las dualidades oralidadescritura y masculino-femenino se reúnen en los dos legados contradictorios del Sr. Ramírez: un testamento escrito en el que deja su verdad a un hombre (Larry) y su donación hecha verbalmente, que tiene a una mujer como testigo (la enfermera). Una imagen capital de la vacilación la encontramos en $L T R H$ ctrando Toto solicita a Berto que lo lleve al baño de varones (p. 33).

${ }_{17}^{17}$ Esther es el desarrollo de un estereotipo femenino que proviene del tango Milonguita. Cf. I. Vilariño, Tangos, vol. I (Buenos Aires: Cedal, 1981), p. 22. Esther tiene su cuaderno manchado de grasa: esto ilustra el calificativo que en Argentina se daba a los obreros peronistas. Otra equivalencia que la novela desarrolla abundantemente (proviene también del lenguaje familiar) es la de comercopular-violar (cf. el monólogo de Cobito). Quien más come es Toto («come todo», «como morfa», «tragalibros»); es un comilón, un morfón, apelativo con que el argot masculino designa a los homosexuales pasivos. La novela calla este apelativo, pero por otro lado trabaja la equivalencia, la exhibe. 
abuelo materno puede matar una gallina, Berto no se anima a matar una araña. "Incapaz de matar una mosca» («araña», en este caso) es la frase que genera la escena y define la ley.

Maldición, con no menos claridad, pero con mayor esquematismo psicoanalítico, reitera esta imagen y la bifurca en las dos voces que hablan. Larry (catálogo de idées reçues) dice de su padre: «tenía una parte buena mansa y otra violenta, ciega. Tal vez porque ante mi madre agachaba la cabeza a cada rato» (p. 44); Ramírez, por su parte, reproduce con su familia las mismas características amenazantes de Berto: «no se animaban siquiera a respirar [...] si yo dormía [...] tenían que permanecer callados [...] yo explotaba en cóleras atemorizantes» (p. 257).

Sin embargo, la ley paterna no es «boba» en lo que se refiere a sus determinaciones simbólicas. Obsérvese que en las siestas (lugar que LTRH piensa como origen) Berto ejerce con sus amenazas apocalípticas una interdicción capital en la génesis de la escritura: su ley es efectiva cuando impide el ruido y la palabra. Hace desconectar el timbre, impone el silencio y obliga a Toto a esfumar su voz o a escribirla (éste, respetando el sueño paterno, dibuja, pinta letras chinas y árabes, p. 74). Silencio que se impone desde el comienzo, cuando Toto aún no habla; las primeras palabras del padre que la novela registra se refieren a la interdicción de la voz: «Hacé callar a ese chico...» (p. 23).

El silencio está en el engendramiento de la escritura, pero también en el molde con que $L T R H$ forja sus personajes masculinos, abrevando coincidentemente en ciertos estereotipos sociales. Un primer corolario de semejante ley textual sería: los hombres no hablan. Un dependiente «bochinchero» inspira tal desconfianza a Berto que «está seguro que no va a durar un mes y lo va a echar» (p. 75). Choli traza el estereotipo cuando describe a su marido: «de pocas palabras, [...] que le gusta estar en silencio al lado tuyo» (p. 67); Herminia sigue el modelo, el marido ideal que no tuvo debería haber sido «callado» (p. 311); y Esther, en su diario, describe a Héctor, prototipo machista, «silencioso como la primera letra de tu nombre» (p. 243). Teté permite corroborar que la ley paterna se conecta con el silencio y la escritura: su abuelo no puede hablar porque tiene parálisis (o bien habla «despacio»); su padre ha sido periodista, tuvo una imprenta y le escribe versos (p. 141).

Segundo corolario: los hombres no cuentan. Berto, en su primera aparición, prohíbe a Amparo revelar que él ha espiado la conversación entre su mujer y Adela. Esta prohibición, tan contundente como la anterior, deja sus huellas en el cuerpo de la sirvienta, reclama juramentos. El mismo se somete a la ley: no enviará la carta, no contará to que ha 
visto, lo que ha sabido. Pero, por ello mismo, su silencio es sujeción al orden femenino, exhibe con claridad que los hombres «no cuentan» (no importan) porque se rinden ante un poder al que se hallan sometidos. La prohibición paterna de contar recae sobre Toto en forma desplazada, es Raúl García quien lo amenaza con «romper[le] la cabeza» (p. 101) si revela la escena erótica que protagonizó con Paqui. Contar lo visto (lo sabido) equivale a ponerse en una posición transgresiva, y Toto («cuentero», «charlatán», «alcahuete») es quien va más lejos en esta transgresión, ocupando el mismo lugar que la novela asigna a Ramos, un amigo perverso de Choli. Ramos («tan educado [...] que ni una niña», p. 61) no sólo exige que Choli revele intimidades de su marido, sino que convierte - como Toto con el cine- un espectáculo teatral en relato (p. 61).

La potencia de verdad que encierran las narraciones de Puig se halla en este núcleo productivo: un transgresor, ubicado en el intersticio de la ley, fabula sobre una fábula y con ello desnuda a la vez la mitificación y el poder opresivo del orden: es lo que cuenta $E l$ beso de la mujer araña al unir dos excluidos, dos exclusiones, dos transgresiones.

\section{El circuito voraz dEL CONTAR}

Escapado de la ley masculina, el contar un espectáculo supone, en este universo, participar de lo que podría llamarse «un circuito narrativo voraz». Unido, por el contrario, al mundo materno, es imaginario, oral y revestido con atributos nutricios. $L T R H$ tematiza la voracidad con las abundantes referencias a la comida que diseminan los personajes (Toto, el «cuentero», es precisamente el más voraz), pero también presenta una escena donde es posible probar que la apetencia es narrativa, deseo de ficción. Mita, enferma, no ha podido ir al cine (p. 149) y describe así ese circuito ansioso en el que se intercambian narraciones: "La puerta de oro' me contó el Toto a la ida y a la vuelta me iba a contar otra que yo no vi $[\ldots]$ y a la vuelta $[\ldots]$ le conté yo. Con los ojos abiertos, abiertos, "más y más' que le contara.»

El beso y Maldición contienen abundantes referencias a la comida; en la primera se trata de un factor ligado con la trama (la comida que Molina, el homosexual, finge traída por su madre es un señuelo concedido por la policía para ganar la confianza de Valentín). El beso, en la voz femenina y «materna» de Molina, hace circular dos elementos que sostienen la estructura narrativa: la comida y el alimento imaginario de 
las películas que relata («me acostumbró — dice Valentín- a contarme películas como un arrorró», p. 285). En LTRH como en Maldición -fuertemente ligadas entre sí- se establece la misma homología entre comer y copular ${ }^{18}$, pero en la última, además, se trabaja con una voz «ingenua» (Ramírez) que "vampiriza» a la obra solicitando relatos, detalles, verosimilitudes realistas: «Usted es como un vampiro, se alimenta de la vida de los demás» (p. 89), dice Larry; «[...] Es como si quisiera que lo llenase de pensamientos, ideas, sensaciones. A veces me da la impresión de que me quiere sorber la vida, como una coca-cola» (p. 55).

Esta voracidad, este vampirismo, pueden leerse en Puig como la representación de su propia «máquina» narrativa (insaciable «compendio de minucias ${ }^{19}$ en cuanto reproducción realista, y especie de fabulosa cascada diegética cuando usa géneros menores u otros códigos narrativos).

Narrar implica en Puig ejercer la seducción, contar es ejercitar un poder que el erotismo confiere; por eso Toto, en su composición, imagina la felicidad amorosa como un intercambio de relatos: «finalmente podrán contarse tantas cosas» (p. 269), dice de Carla y Johann, la pareja protagonista de «la película que más [le] gustó». En El beso está claro que la donación de alimentos y relatos es el mecanismo seductor que Molina despliega para atraer a Valentín, pero en esencia se trata del mismo artilugio con que el homosexual Ramos -otro relator de espectáculos- ha fascinado a Choli. Sin duda, en la narrativa de Puig el lector, ante todo, debe ser seducido, atrapado en los efectos de un contar que se define como posición "femenina». El poder de la fabulación se muestra en su origen ligado a una frase del lenguaje infantil: a los niños que dicen mentiras les salen jorobas o les crecen colitas. Toto evoca con complacencia esta amenaza, que en vez de horrorizarlo lo fascina: luego de recordar con odio a su maestra, que blande un puntero, en sucesión metonímica, aparece la mentira y su consecuencia, la colita. El capítulo concluye con una imagen de poder: Toto, entre las nubes, ve pequeñito a Vallejos y, como revancha, «la maestra con el puntero está chiquita abajo en la escuela» (p. 47). Toto siente crecer su propio poderío: la fabulación, la ficción.

Hay una escena matriz en $L T R H$ donde se concentra una enorme cuota de deseo (deseo de comunicación, deseo narrativo y erótico); es

${ }^{18}$ «Una vez le pregunté al médico sobre esas sensaciones [sexuales]. Me pidió que pensara en una comida muy apetente...» (Maldición, p. 75).

19 Alicia Borinsky, Ver/Ser visto (Notas para la poética) (Barcelona: Bosch, 1978), p. 58. Se refiere a El beso de la mujer araña. 
una fantasía de intimidad con Raúl García, forjada por Toto como una película de aventuras:

[...] y me salva y en la cabaña tiene preparado un cívico con sánguches de miga [la comida], y yo le cuento todo como es Buenos Aires y después todas las noches le cuento una obra distinta y después empiezo a contarle cintas... (p. 91).

Si el mundo de Raúl García se presenta previamente como el reinado de lo pura y exclusivamente masculino («no tiene madre», "viven los dos hermanos con el padre [...] y no se hablan nunca», pp. 91-92), si los hombres no hablan ni cuentan, el deseo de hablar y narrar se teje sobre la necesidad de intimar con la figura paterna (los «sánguches de miga» son los que Toto no comió cuando luego de ver «Sangre y arena» no fueron con su padre a la confitería, p. 88). Escena matriz porque permite desarrollar situaciones que llamaríamos «de intimidad coloquial entre hombres solos»; ésa es la estructura que sostiene El beso de la mujer araña y Maldición eterna a quien lea estas páginas, donde justamente dos hombres hablan y cuentan, revirtiendo así lo que en $L T R H$ se daba como situación escamoteada.

\section{LAS RELACIONES PELIGROSAS}

Maldición es en su anécdota un diálogo entre dos hombres que intercambian alternativamente los papeles de padre e hijo en una estructura circular e imaginaria: el pasado de Ramírez sirve como referencia paterna a Larry, pero la indefensión casi infantil del argentino lo constituye en hijo. Re-escribe $L T R H$, y no es una figura retórica: el eje de la relación son unos libros sobre los que Ramírez ha escrito en clave; allí en particular reproduce una carta del hijo, lamento de decepción y reproche. Esta Carta al padre de la literatura hispanoamericana actual (Angel Rama) ${ }^{20}$, en verdad continúa la carta de decepción y reproche que escribiera Berto, carta que no es del padre, sino al padre, pues está dirigida a su hermano mayor, que ha oficiado como tal. Con Maldición se escribe en clave sobre Les liaisons dangereuses (novela epistolar), se vuelve sobre el tema de la carta y las relaciones peligrosas, que no son sólo las familiares. En efecto, la pérdida de la memoria del argentino

${ }^{20}$ Angel Rama, «El diálogo imposible», en Sábado (suplemento de Unomásuno), México, 21 noviembre 1981. 
convierte su pasado en referente vacío o vaciado, signo de una zona de la que no se quiere hablar. Otra relación peligrosa.

Puig, que en sus narraciones siempre se ha preocupado por insertar la historia política argentina (el centro es el peronismo), a partir de Pubis angelical la hace girar en torno a personajes enfermos que determinan la trama; significativa inmovilidad en Ana, amnesia en Ramírez: congelamiento y olvido.

En $L T R H$ se liga la escritura con la memoria: Toto posee una memoria excelente (p. 112) y Herminia parece desarrollar —negándolauna teoría de la escritura como huella material en los cuerpos: escribir es recuperar el cuerpo que el enunciado representa como oculto, «transparente», o tapado. $L T R H$, al volverse cronológicamente sobre el pasado (1933-1948-1933), ostenta en su estructura temporal ese gesto de rememoración, de recuperación que ha emprendido el sujeto de la escritura. Se rememoran las relaciones familiares y sociales. En cambio, Ramírez, narratario minucioso, voraz y realista, pretende saber qué hay dentro de una canasta de picnic y luego qué dentro de los emparedados; "no hay nada adentro, cubren un hueco» (p. 185) es la respuesta de Larry, que inscribe un vacío referencial (el reciente pasado argentino es un débil marco sin desarrollo narrativo), pero también un «hueco» lingüístico: los personajes hablan una jerga neutra, sin localismos ni sabor. Si «la vida social entra en correlación con la literatura, ante todo, por su aspecto verbal»" ${ }^{21}$, Maldición deja sólo en pie las relaciones familiares centradas en la filiación masculina.

En Boquitas pintadas, cerca de la tumba de Pancho, que ha muerto dejando descendencia, florece y da frutos una higuera ${ }^{22}$; en su primer paseo Ramírez se interesa por un árbol y luego lo sueña cargado de fruta (pp. 10-11); en la carta final Larry menciona «la buena semilla de su consejo que germinó por fin» (p. 278). Se trata, obviamente, del árbol genealógico, que se ubica en Maldición fuera de la familia y de la sangre.

La metáfora paterna determina toda la estructura de Maldición, cuyo mecanismo básico es la sustitución: un padre que se vuelve hijo y viceversa, el destinatario de la carta final reemplaza a Ramírez, éste intenta suplantar a Larry por una enfermera, los diálogos alucinatorios del viejo tienen como tema la rivalidad y la sustitución filial, uno intercambia su vacío de pasado con el vacío de futuro del otro, etc.

${ }^{21} \mathrm{~J}$. Tynianov, «De l'évolution littéraire», en Théorie de la littérature (París: Seuil, 1965), p. 131.

${ }^{22}$ Edic. cit., p. 285; J. Ludmer, op. cit., p. 13. 


\section{LA VERDAD Y LA FICCIÓN}

Son los excluidos o los transgresores quienes en $L T R H$ escriben y trazan una concepción de la escritura ${ }^{23}$. A la etérea y ascensional fantasía cinematográfica se opone la memoria y el cuerpo (Cuaderno de Herminia), el trabajo y la conciencia política (Diario de Esther). Esta última reproduce los delirios de ascensión que proliferan en la novela, pero al enmarcarlos en su condición proletaria, revela que, en el fondo, lo que mueve a todos los personajes es un anhelo de ascenso social. La política es el deslinde que permite separar los ilusorios devaneos de las condiciones concretas que los generan. A través del Diario de Esther, la política penetra en la novela desenmascarando las ilusiones; fantasía y realidad tienen por primera vez una barrera que franquea o impide el pasaje entre una y otra, es el dinero: "Las vi [unas telas importadas] realidad y sueño netamente separadas por un cristal de escaparate» (p. 260).

En el Diario de Esther se menciona una escritura de la mentira y del ocultamiento, una escritura que «tapa», que se ubica del lado de la ley y de la ñoñez pequeñoburguesa, la asume una profesora de castellano:

no me venga usted - dice Esther- con que hay que ocultar al trabajador y su sudor, y alabando a ese rascacielo porque oculta de la vista de los ricachones [...] el espectáculo feroz [...] del trabajo (pp. 261262).

Es el discurso político el que devuelve la conciencia del cuerpo, uniendo materialidad, escritura y lucha de clases. Así lo indica la transcripción hecha por Esther de un discurso peronista ${ }^{24}$ :

... la oligarquía verá las necesidades del obrero aunque éste tenga que abrirle de un machetazo el cráneo y escribirselo en el seno con los dedos; y la tinta será su misma sangre oligarca (p. 262).

La moral del disimulo que asfixia a los personajes con sus consignas

${ }^{23}$ Esther no irá con los demás a la Confitería Adlon. Cobito escribe un anónimo: ha sido expulsado por transgredir el orden (se burló de un celador, p. 256). Berto ha sido excluido de los estudios por su hermano y queda al margen cuando las dos mujeres "confabulan». Herminia está excluida del sexo y hasta de la vida: aparentemente «espiritual», es el exacto negativo de la materialista Delia: la presencia $o$ ausencia del sexo, el sueño y la comida es lo que permite oponerlas. Novela primeriza, $L T R H$ parece conjurar mediante esta artista fracasada el peligro de un fracaso artístico.

${ }^{24}$ En Esther hay parodia, pero no es el peronismo en sí lo parodiado, sino la sublimación populista que espiritualiza la noción de pueblo, otorgándole un alma, un corazón, un soplo. Una ideología sentimental, paternalista y, finalmente, reaccionaria. 
queda develada por otro registro de discurso, cuyo efecto es situar concreta y socialmente cualquier fantasía.

La escritura se piensa en Puig como un producto material que muestra su íntima ligazón con el cuerpo, la memoria, el trabajo y la verdad. Cumple siempre una función develadora, aclaratoria, desalienante, echa luz sobre la confusión o la ceguera en la que se mueven los personajes de clase media. «Pero poniendo todo por escrito me ayudo a ver más claro», afirma la atribulada Ana de Pubis angelical, luego que el politizado Pozzi le revela "brutalmente» lo incurable de su enfermedad.

Perseguido, Toto no sabe si es culpable o no, no entiende la película que cuenta por escrito a su madre - «Cuéntame tu vida»-, cuyo protagonista con «una nube en la memoria» huye por crímenes que no cometió. $L T R H$ por entero se muestra como un «contar la vida» por escrito de quien enhebra todos sus episodios, para no olvidar y para entender los equívocos de una ley que persigue -como el contradictorio señor feudal- a aquellos mismos que ella ha engendrado. Lo importante es que la ficción contiene la verdad y que ésta refulge en la escritura.

¿Y la escritura de Toto no es acaso la ilusión y la ceguera? Ficción en segundo grado, espejo textual, la composición se construye con los residuos que la novela desplegó, códigos de clase, ideologías, lenguajes, prejuicios, ficciones. Narrar una película es adherir al relato las proyecciones imaginarias que desnudan al narrador. Están ahí reconocibles en forma de lenguaje sin dueño, dialogando entre sí, porque en realidad, LTRH no tiene monólogos, toda su estructura -incluyendo los monólogos- consiste en desplegar voces y lenguas que hablan por sí mismas para exhibir las ideologías en las que están encarnadas. La verdad se habla y se escribe y «tiene estructura de ficción» ${ }^{25}$.

$\mathrm{Si}$, como vio Bajtin, la novela es el género dialógico por excelencia ${ }^{26}$, si la novela se constituye a partir de un diálogo que es el entrecruzamiento, las alianzas, mezclas y pugnas de la ideología, nadie, entonces, en la literatura argentina actual, ejecutó mejor este despliegue de voces encontradas y desencontradas que Manuel Puig.

${ }^{25}$ Frase de Jacques Lacan, quien retoma las teorías de Jeremy Bentham: «el hecho de la operación poética debe hacernos detener en el rasgo que ciertamente se olvida, es que la verdad se confirma en una estructura de ficción», en "Jeunesse de Gide ou la lettre et le désir», Écrits (París: Seuil, 1966), p. 742. «De otro lugar y no de la realidad es de donde la verdad extrae su garantía: de la Palabra. De ella recibe la marca que la instituye en una estructura de ficción», op. cit., p. 803 («Subversion du sujet et dialectique du désir dans l’inconscient fretidien»). Traducción mía.

${ }^{26}$ Cf. Mikhail Bakhtine, La poétique de Dostoievski (París: Seuil, 1970) y Esthétique et théorie du roman (Paris: Gallimard, 1978). 
